\title{
Uncovering The Factors Influencing The Technological Adaptation of Twitter Usage Among Journalists in the Transforming Journalism Practice
}

\author{
MASSILA HAMZAH \\ IMA LIANA ESA \\ Universiti Teknologi MARA (UiTM), Shah Alam
}

\begin{abstract}
The increased usage of digital technologies has radically impacted the journalism profession across the globe. This qualitative study focuses on the factors influencing the technological adaptation of Twitter usage among journalists in the transforming journalism practice. To gain insights on the central focus of this study, ten (10) local news journalists at the News and Current Affairs Media Prima Berhad (NCA MPB) with professional profiles on Twitter were interviewed. Data analysis were conducted simultaneously with data collection and the NVivo 10 software was used in the coding process. Thematic analysis was employed to analyse the data. Findings revealed THREE (3) significant themes that contributed to the technological adaptation of Twitter usage among journalists, as follows; (i) willingness to collaborate (ii) technology acceptance gap, and (iii) institutional readiness and encouragement, which plays a salient role in facilitating the adoption process as well as bridging the technological gap among the journalists. An interesting finding in this present study warrants that institutional readiness is necessary to understand journalist's propensity to embrace and use cuttingedge technologies, from being a conventional journalist to adapt self and engage in the digital realm. With the blossoming platforms due to online boom and social media, journalists must embrace technology as an enabler for their professional relevance and the news industry survival. In conclusion, the institutional readiness is therefore necessary to ascertain the journalist's propensity to embrace the cutting-edge technologies in performing their challenging role in the changing media industry today.
\end{abstract}

Keywords: Technological adaptation, Twitter, journalism practice, qualitative, media industry.

\section{INTRODUCTION}

The increased usage of digital technologies has radically impacted the journalism profession across the globe. At the core of transforming newsroom into a global platform is the technological adaptation towards this fast-paced digital world. As the nature and culture of newsroom continue to evolve, the definition of journalism practices challenging the roles and responsibilities of journalists. Today, a growing part of a journalist's daily reporting takes place within the spheres operated by the major social media providers. Regardless of the platforms, it is evident that all news content today depended on digital technologies which are highly interactive and flexible. Thus, journalists are able to thrive their creativity in creating their uniqueness in curating news angle.

Indeed, the significance of technological adaptation among journalists has been associated with a complex, dynamic and evolutionary process of how an individual cope with cultural change caused by technology (Wan Hartini, 2018). Likewise, the adaptability of digital technologies by news organizations offers a new platform for reaching strategic mass audiences. In observing the fact that the media industries play a critical part in newsgathering and news-processing routines (Saad, 2017), therefore the implications of social media on the transformation of the media industry today is essential to be studied (Eni, Detta, \& Siti, 2020). 
Among the social media sites, Twitter has evolved as a successful platform and the majority of television newsrooms are utilizing Twitter with high frequency. Considering Twitter assisted the attainment of information on newsworthy events, news reaches the masses in real-time. Indeed, today's media channels adopted the social media platform of Twitter (Groshek \& Tandoc, 2017) to connect with larger audiences. As a result, journalists today leverage Twitter usage not only to interact with their viewers and readers but also in identifying ideas for stories (Canter \& Brookes, 2016; Heravi \& Harrower, 2016). In the sharing of breaking news as well as real-time information, Twitter and other social media play an important role in the daily news production and journalism practice (Çatal, 2017). Twitter has brought a unique closeness between journalist and their audiences through real-time tweets. It now becomes a window of the world in sharing the latest events from all over the globe, and news often breaks first on Twitter. Additionally, engagement goes further by responding, retweeting or soliciting news tips. As such, a journalist's role and responsibilities today are bounded by the number of followers and tweets.

This study centres upon the primary objective of uncovering the factors influencing the technological adaptation among journalists in the transforming journalism practice focusing on Twitter usage in performing their role and responsibilities.

\section{PROBLEM STATEMENT}

Traditionally, the role of conventional journalist started with creating a piece of news from a substantial event or issue by going down to the location (Doctor, 2011). Indeed, the usergenerated content and social media platforms are gaining popularity, which has led to the evolution of the traditional practice of obtaining information and news curation process from official sources. For one, the digital revolution pushed media organizations to experiment with new ways of presenting news formats.

With the changing media landscape, the journalists as news producers are faced with an ongoing challenge, especially the predicaments faced by journalists in adapting to the new norm from the traditional method of creating a piece of news into a digital platform. More importantly, the changing work culture in the news industry has indeed changed the business model involving the works of journalists as news producers.

To attract the audience's attention, they must make their content available to search engines and other social media platforms through revenue and returns are affecting the news ecosystem. Likewise, the usage of Twitter in the newsroom has transformed the gatekeeping process and eventually, the digital media are transforming how journalists and other communication professionals perform their work and to succeed in the practice of journalism, media organizations have no choice, but to keep abreast with the fourth industrial revolution technologies (Normah, Shahrul Nazmi, Ahmad Sauffiyan \& Mohd Zuwairi, 2017). Indeed, journalists in this digital era are challenged by the changing tools in news curation which implies an indirect evolution in their roles (Bruell, 2012) as news worker. For a journalist, the ability to produce a seamless combination of text, photographs, sound, video and any other types of information has made the news curation and presentation on Twitter more interesting for today's audience. With the latest state-of-the-art technology, journalists can express their creativity in merging of text, photographs, sound, video and pictures into digital form. 
Blut and Chang Weng (2019) in analysing technology readiness posited that innovative pursers seek to learn about new technologies, and thus tend to better understand how a technology works, leading to perceptions of needing less effort in use. As such, the concept of mobile journalism (MOJO) allows journalists to be multi-tasking, that involves the ability to report, write, capture pictures, and edit news stories by themselves, a job that is traditionally done by a team of an assigned crew (Blankenship, 2015).

Apart from skills, Lee, Lindsey, and Kim (2017) posited that the regular newsroom activities demanded one to acclimatize to social media utilization especially the journalists of all stages. Likewise, Wu (2018), revealed that in their 20s and 30s, journalists desire to adapt to social media and interest in social networking is higher as compared to the senior journalists who ignored the usage of social media in their daily work. According to Wu, senior journalists are contended with their positions as a more traditional journalist to learn new skills and adaptability is a challenge when they hardly use the new media in their daily routines.

The decentralization of media has created a group of audience to become highly selective in choosing any news and this has become a critical part in newsgathering and newsprocessing routines in the news industries, locally and internationally. Normah et al. (2017) posited that the media users today have reached an age where media users are no longer a 'passive-watcher' due to the various alternatives through the usage of the ever-changing technologies. This fulfils the changing needs of audiences that are inclined to look for creativity in news being presented on social media apart from being the fastest indicator of breaking events and the vastness of choices from various dimensions. Hence, the challenge lies in how to present stories in the most effective, powerful, innovative and creative ways to continuously engage with the media users.

Traditional media players such as the print newspaper industries and television stations are currently facing hordes of challenges in adapting to the transition of their business and investments on the digital landscape for survival and most importantly, to be in line with the current changing needs. Therefore, to keep up with the new pattern of media users, news channels use Twitter to disseminate news, promote stories, and acquire new clients. Journalists, on the other hand, use it as a tool to find and reach out to sources (Hanusch \& Bruns, 2016).

Given the various state of the disruptions, Media Prima Berhad (MPB), being Malaysia's biggest media conglomerate, operating all four free-to-air television channels in the country is of no exception. The fact that Media Prima Berhad controls almost 90 per cent of the nation's free-to-air advertising. The company also owns three major newspapers English-language New Straits Times, Malay-language Berita Harian, and Harian Metro, the predicaments faced by journalists in adapting to the changing work culture is worth to be studied.

\section{PAST RESEARCH}

A lot of researches conducted across the world to investigate the influence of Twitter on news perception and roles of journalists in the digital era, more so after major news channels such as CNN, Al Jazeera, BBC, and Sky News created their Twitter accounts in 2007 (Bro et al., 2015; Canter \& Brookes, 2016; Hanusch \& Bruns, 2016; Heravi \& Harrower, 2016). In the local context, Malia and Teh (2020) in their exploration on the changes of the media landscape in Malaysia highlighted the contributing factors, namely instant gratification of the news such 
as the changing mode of transmission, new writing styles, the open and freer media landscape and the transforming gatekeeping process.

The adaptability of utilizing Twitter in news dissemination has been found in research by Hanusch and Bruns (2016), Heravi and Harrower (2016), Lee (2016) with Molyneux, Holton and Lewis (2017). In utilizing Twitter, factors such as journalists' attitude towards technologies, the openness of new job role and the role of news organizations in encouraging journalists in adapting the social media as a part of their daily reporting were highlighted. In the research carried out by Kröll (2015), social networking sites such as Facebook and Twitter have emerged as the news routes facilitating journalists to keep up-to-date with wide-ranging news as well as social trends. The study was supported by Canter and Brooks (2016) who proclaimed that additional news agencies utilized Twitter as a creative tool for procuring information, reporting as well as for disseminating newsflash. The role of the journalist is to establish a relationship among the tweet styles as well as the performance of the role of a journalist.

As Twitter was launched on July 13, 2006, it has emerged as an eminent medium of delivering information across the world. Raj et. al. (2015), stated that Twitter has previously been operated as a toolkit by news corporations and journalists for broadcasting news for approximately a decade based on observation of journalists in India tweeting habit. Findings in the research claimed that this new changing landscape demanded journalist to acclimatize with the evolving medium and exploit Twitter instantaneously for information. Findings by Bentivegna and Marchetti (2017) cited that at present, journalists adapt to social media in rendering the newsroom obsolete by facilitating journalists to send their information from any corner of the world. This content-analysis study stated that Twitter performs an intricate part in analysing news cycle since it produces such huge spreads of information. They also concluded that this is true for journalists who are using Twitter to intensely look for the authenticity of each information and its credibility to be shared with the rest of their audiences.

The adaptability of utilizing Twitter in news dissemination was also cited in the United States as the earliest country to use Twitter as a novel medium to disperse news and to report to a catastrophe. This can be found in an observation-based study by Heravi and Harrower (2016), that when the Southern California wildfires occurred in October 2007, several news agencies exploited Twitter to disperse key sections of information, like evacuation orders, shelters as well as fire-fighting, to huge crowds of the mobile population.

In this present study, the contribution of journalists to highlight the news on Twitter is greatly shaped and influenced by various contributing factors. Researchers also instituted that the industry players play an imperative role in supporting the journalists during the transformation process of changing work culture among journalists.

\section{METHODOLOGY}

This present research employed a qualitative method and in-depth interview were used for collecting method. The samples were selected through purposive sampling, as stated by Creswell and Poth (2018), that specific informant provided the researchers with some preferred information for research purposes. As such, journalists servicing the Current Affairs Division Media Prima Berhad (NCA MPB) were interviewed. Data analysis were conducted simultaneously with data collection and the NVivo 10 software was used in the coding process. Thematic analysis was employed to analyze the data. Input from all respondents was 
transcribed and analysed. After compiling the data, analysis of the findings were deliberated to derive to the outcome of the objectives. As posited by Ness (2015), data saturation differs from one research to another and that it will be determined when there is no new coding, hence no further information or themes found after the same answers were repeated by informants throughout the interview session.

\section{FINDINGS AND DISCUSSIONS}

Analysis to establish the findings in this research was undertaken after the data collection stage was complete. In-depth interviews were conducted comprising of ten informants, from News and Current Affairs Division Media Prima Berhad (NCA MPB). Each informant has had a unique view and vast experience in utilizing Twitter in performing their tasks in various departments and work experience in MPB. The in-depth interviews took approximately six (6) months to complete. Each interview was conducted in an informal session yet structured, providing insightful information and experiences from the respective informants. The interview session was recorded and transcribed verbatim. In the search for themes, Nvivo10 software was used to manage the data. Views from each informant are deemed important current developments.

Contributing Factors to the Technological Adaptation of Twitter Usage among Journalists

Twitter has evolved as one of the most popular micro-blogging platforms that permit users to connect people simultaneously via short messages, known as 'tweets.' Indeed, Twitter has become part of an important media system where users receive news and information from all around the world (Chadha et al., 2016). It broadens information reach to the public, discover sources and eyewitnesses, along with monitoring social media for current news (Canter \& Brookes, 2016). The fact that Twitter has evolved as an essential toolkit for journalists, it has been extensively utilized in newsrooms (Raj, Sreekumar \& Kalorth, 2015).

In the case of Media Prima Berhad, the News and Current Affairs Division initial utilization of Twitter as a platform were initiated in August 2018. The mission then was focused on enhancing the presence of the station on social media and engaging with its loyal viewers. Hence, the need to integrate news coverage into the social media platform especially Twitter was deemed necessary for Media Prima Berhad (NCA MPB). Such mission aims to maintain its relevance as a renowned media industry in Malaysia.

In comparative, among the mainstream television in Malaysia, TV3 was the first station to launch their Twitter account @BuletinTV3 in June 2010, followed by Bernama News Channel (BNC) Twitter, @BernamaNC, in September 2010, Radio Television Malaysia (RTM) @beritartm in March 2011, TV9 @BeritaTV9 in November 2011, ASTRO AWANI @501Awani in February 2012 and NTV7 @7Edition_ntv7 in July 2013. In 2012, ASTRO AWANI took a strategic step, in a bid to gain more followers, by promoting its journalists' personal Twitter accounts. Comparing the six mainstream media Twitter accounts, ASTRO AWANI Twitter account has the highest number of followers with 1.6 million, which trailed distantly by TV9 at 695.9 thousand followers. Having journalists on the site, reporting directly from their Twitter accounts have created immediate impressions (Malik \& Pfeffer, 2016).

Based on the in-depth interview, various factors contributed to the adaptability of utilizing Twitter to disseminate news among the journalists at New \& Current Affairs Media Prima Berhad (NCA MPB). 
Highlighting the summation of themes in this research, the contributing factors to the adaptability in utilizing Twitter to disseminate news among journalists at NCA MPB were revealed. Data analysis were conducted simultaneously with data collection and the NVivo 10 software was used in the coding process. Based on the thematic analysis employed to analyze the data, findings revealed THREE (3) significant themes that contributed to the technological adaptation of Twitter usage among journalists, as follows;

i. Willingness to collaborate

ii. Technology acceptance gap

iii. Institutional readiness and encouragement

\section{i. Willingness to Collaborate}

Driven by the shared challenges of new technologies adoption in the newsroom, peer engagement and collaborative effort play a huge role in facilitating the adoption process as well as bridging the technological gap. Journalists take pride in performing their tasks especially in content capturing and sharing information and in the context of MPB, the role and responsibilities of journalists is to curate news and writing stories for two mediums: news for television broadcasting and digital storytelling for social media. This means, the required growing media skills to be trained, equipped and literate to multi-platform tools and to democratize MOJO skills become vital.

In a research by $\mathrm{Wu}$ (2018), age was determined to have a strong influence towards the journalists in utilizing the benefits of social media and the massive technological mismatch can hamper newsroom flow and complicate the news operating environment. In the context of this research, the age gap between junior journalist and senior journalist in Media Prima newsroom was found to be a factor in determining the adaptation level. This is due to the perception of senior journalists that news published on traditional media is more reliable than the social media platform.

Besides that, the readiness to adapt to the rapid change of technology is evident especially among those who served the industry for more than 20 years. Comparatively, junior journalists who served the newsroom between three to five years found it to be a manageable task. Adoption in technology usage assisted in performing their tasks as a journalist, as cited in the following excerpts:

\footnotetext{
"ehmmm, I don't use Twitter to update news, to be honest, I hardly engage with people through social media. It takes me around six months to familiarize with it. But now I am okay... I am open to this change ...hehehe" (SMJ 6, 2020). "Sometimes it's is a hectic situation in the assignments. I find it hard to tweet because I have a lot to do simultaneously in location. It's like a burden at first but I'm trying to get used to it" (SMJ 2, 2020).

"I already have a Twitter account since high school. It's normal for me because I love to express anything on Twitter. Ehmmmmmm, but I like to separate my personal and professional role, so I created the account...... One for personal use and one for work." (JMJ 7,2020).

"Yahhh, I work as a social media manager before. So of course I can handle it easier. I think MPB should transform to this long time ago. Awani had started it long ago, so it's kind like we miss something if we don't try to conquer this new medium." (JMJ 8, 2019).
} 
In addition, engagement to familiarize self between the senior journalists and the junior journalists were found to assist in the news dissemination process. Here, a collaboration between both seniors and junior journalists were apparent whereby, contribution toward content writing and the merging of their expertise in utilizing the social media platform were executed by the junior journalists. In observing the changing journalist practices, aligning their skills in basic writing, photography, or video is vital. In order to remain relevant, having the right skills-set and fit into the digital era, journalists must be well trained, having sound knowledge is vital and most importantly is the willingness to learn new skills. As such, in a seamless world, a journalist can broadcast the news from anywhere in the world across time and space.

\section{ii. Technology Acceptance Gap}

Reflecting upon the journalist's role a century and a half ago, Canter and Brookes (2016) cited that communication between journalist across countries requires physical presence, be flexible and had to run back and forth to deliver news after interviewing to be able to beat the competition to broadcast the news among news stations.

With the advancement of new technology, journalists in the news industry are confronted with new demands and role expectations. At the core of self-improvement and journalistic survival in this new journalistic culture is the readiness to bridge the technology gap. However, age posed a significant gap in utilizing Twitter in performing their task. Such issue was cited by Wu (2018) in her research about the adoption of social media as an innovation in the journalism industry where age differences are the main factor that affects journalist adaptability towards the utilization of social media. However, in this present research, efforts to familiarize self with the new skills are evident and the realization to collaborate their expertise and technological skills is a practised between the seniors and junior journalists. as cited in the following excerpts:

\footnotetext{
"ehmmm..hard for me at first. I'm not kind of social media person. But I try to learn as more people are now searching for news on the digital platform. Like it or not we also must learn to use it from others." (SMJ 5, 2020).

"for senior journalists, we might have a problem to get used to the new roles. But with time and effort I have no problem to tweet from the location. I love to do it" (SMJ 3, 2019).

"yahhhh, no, I don't have a Twitter account before, but when I got one set for us, from the management, I learn and I'm excited now hehehe.... And I try to tweet whatever info I get. Even though it is not an assignment that I covered. (SMJ 4, 2019).
}

For young journalists, covering the news in real-time across various media platforms is similar to their daily engagement with technology. Being born in the technology era, leveraging Twitter in completing their tasks and building a reputation through a good amount of followers on social media is important. The engagement with followers was cited as follows: 
"I tweet before I go to assignment to let my followers know what I'm doing on that day" (JMJ 8, 2019).

"Sometimes, the public is a reporter's best source for leads and information. we can scoop some issues" (JMJ 9, 2019).

"I tweet on location. I tweet to gain attention from viewer to watch my story that night. No problem to tweet.This is a good reputation for us and the station too" (JMJ 10, 2019).

Responding to strategies of senior journalists manage their daily reporting with the need to be multitasking, the various outcome was revealed. The realization was shown by both groups of journalists involving time and effort in performing their tasks and understanding the importance of a media industry such as MPB journalists is evident. Their views were cited in the following excerpts:

"Ehmmmm, yeahhh I feel hard to focus on two tasks at the location. The boss might think it is easy, but sometimes the situation at the location is uncontrollable. To be honest I only get a chance to tweet after I came back to the office" (SMJ 10, 2020).

"I don't know how to manage at first. It is a challenge for me to tweet at the assignments given. Ehmmm but I did try to get used to it, but still....its takes about a year to familiarize self with the new changes" (SMJ 2, 2020).

"Ahhh, no... before this I already started tweeting about what I'm covering on Twitter. My personal account. Not every day, only on special assignments. But yeahhh, you know, when it started I have no problem at all. I can tweet immediately" (JMJ 4, 2020).

"I'm ok. No problem. I'm active on Twitter before but rarely post about work, just personal thoughts and opinion. I just change my personal account to my professional account. I want to keep my followers. So no problem. It's not hard to tweet and focus on the assignment" (JMJ 5, 2019).

Laor and Galily (2020) described that through social media, journalists could easily share important information to improve and highlight their career interest and ideas. It also helps in exchanging pictorial illustrations, news, and vital information with the public instantaneously. Hence, any journalist with Twitter account who goes out to any events would cover the story and instantly post it on Twitter. Here, one will multitask and are expected to submit news for multiple platforms for broadcast and also posted on online. This requires journalists to be agile, flexible and most of all they must be versatile, to provide stories for both media, the conventional mode and eventually, via Twitter.

The positive newsroom work environment was cited by respondents to be a salient factor to the adaptability in utilizing Twitter among journalists. This is evidently observed in the editors' tolerance and support by not setting any time constraint for journalists to publish their stories in their Twitter account. The collaborative efforts by journalist and editorial team. Knowledge sharing from the senior journalists and the editorial team is evident in deliberating the art of reporting. The assistance of senior journalists as mentors with years of experience was expressed in the following excerpts: 


\begin{abstract}
"ahhhh, you know. It's not easy to add up another job scope in your daily role. I had a hard time to tweet as I always busy on location to interview and get information. Sometimes I forgot to tweet until my superior reminds me. I'm getting used to my new role" (SMJ 6, 2020).

"for me of course newsroom culture is important. I follow my senior when I just started my job here. The way he prepares for the story, the flow of writing. If you get understanding senior, then work becomes easy. We help each other, vice versa" (JMJ 10, 2019).

"ehmmm of course, sometime newsroom culture shaping in how the junior journalist will be. They follow what senior does. But here I think vice versa. I learn a new think about how to use social media or search engine from junior. A sure compliment from the boss is another you want to hear to feel appreciated" (JMJ 9, 2019).

"We must be ready to adapt to these changes. Social media is a close medium to youngsters now. So it is important to adapt with this changing role" (SMJ 3, 2019).
\end{abstract}

It is evident that positive attitudes towards technology among journalists were utmost importance as they are a critical component to the successful operation of technological systems. Technology usage in the workplace can be considered a burden if the attitude towards it is negatively adopted. Hence, journalists are predicted to keep on the trend, improvise and always be resourceful in their job (Laor \& Galily, 2020).

\title{
iii. Institutional Readiness and Encouragement
}

Hanusch (2019) highlighted the fact that newsroom work culture is essential, which means leadership teams must look for ways to work across teams in the newsroom. To realize the full benefit of technology that must be highly valued in the media institutions, readiness and encouragement in migrating the transformation in a gradual manner into a new business model is deemed necessary.

Based on the findings, the NCA MPB work environment is accessible in any way and influenced their adaptability towards uplifting the usage of social media. The newsroom work culture contributed an important part in journalists' recognition of social media as a certified instrument in their newly learned skills. This involves a readiness to accept the disruptions in news curating process, uniqueness of news presentation and dissemination methods via new technologies.

It is also important to note that Media Prima Berhad journalists are mostly equipped with a tertiary degree in relevant fields and graduate with the relevant skills for the job. The majority of them grew up with the Internet, and some of them were familiar with social media before they became journalists. Most have profiles on Facebook or Twitter or both. Social media was introduced and later used by them out of personal curiosity or through the need for it for socializing with their family, friends, and also their fans. Their background input on computers and social media was similar, although their personal history and experiences may differ in the newsroom (Deuze \& Tamara, 2018).

The MPB management in their transformation plan started with the first step by creating a Twitter account for the four news channels under their umbrella, which are @BuletinTV3, @BeritaTV9, @7Edition_ntv7, and @8TVnews in 2010 to keep up with the 
changes in the journalism landscape in disseminating news updates. The increasing number of followers in MPB's four news channels' Twitter accounts has led the MPB management to take a step further by creating journalist's personal Twitter accounts in August 2018 to promote their journalists. At the same time, this new strategy offers the viewers a faster update from locations by the journalists on duty in real-time.

However, in the beginning, some journalists found themselves to be challenged by the transformation plan and cited that it is too difficult to keep up with the existing tasks, which is to tweet updates from locations and simultaneously doing reports on site. Such a challenge is due to many reasons such as juggling their roles and taking the responsibilities while at the location as well as coping with interviewing to collate information.

In the findings, it was revealed that institutional readiness reflects a strong theme to articulate the acceptance of journalist to adapt to technological change. Twitter usage motivate journalists to tweet or post a story with the aim to get more 'retweets,' and as such, the organization need to support and encourage their journalists to utilize social media. The deliberation was cited in the following excerpts:

"ehmm.... I feel much appreciated if I receive compliment by management if my tweet gets higher view or retweet. This positive culture should always be continuing. It gives me the courage to do more" (SMJ 5, 2020).

"of course we will happy if we get compliments from the boss. It is important working in a positive environment and this must be a newsroom culture. Continuing in future" (JMJ 8, 2020).

The findings of this present research suggested that media institutions dealing with news in the changing working cultures will have an impact on journalists' social media engagement. It was revealed that in getting the acknowledgement and recognition from their management team (superiors) on their engagement and usage of social media, both junior and senior journalists admitted that it increases their credibility and motivated them to perform more. When given enough assistance and support, they showed that although it took months to learn and familiarize themselves with the new skill, they are inspired to perform well in their tasks as journalists.

Closely associated with institutional readiness and encouragement is the attitude to accept changes as structured by the media industry. As cited by the Elias, Smith and Barney (2012) defined attitude as a form of judgment by an individual that favourably or unfavourably assesses an attitude object, which can be concrete (e.g. the Internet) or abstract (e.g. technology). There is an obvious bias among the vast majority of individuals towards attitude objects which are evaluated positively, with negatively evaluated attitude objects being typically rejected.

Initiating a high-impact transformation plan is far more important in ensuring the industry's survival and competitive agility are executed with equal strength across growth, profitability, and sustainability. For MBB, the new social media platforms Twitter were put in place and at the same time, they must also be ready to accept the technology as another medium to disseminate news in the current journalism landscape. The views of journalist were cited in the following excerpts: 
"ehmmmm you like it or not, this is what the audience's need and MPB realized this Youngster didn't wait for primetime news to get info. They look for it at social media. We should start this early, but better late than never" (SMJ 3, 2019).

"You know....ehmmm, choosing Twitter as another medium from us to disseminate news or let them know what is happening in real-time is a must in today age. Technology is everything. Our management team realized this from the beginning" (JMJ 10, 2019).

"Even though I don't favour this platform, I admit that this is an area we must conquer. I don't have a problem to learn that, but to make it a habit is the big problem... hahahah... But I cannot deny social media is important...The newsroom encourages this" (SMJ 1, 2019).

The nature of Twitter as a flexible and versatile tool for journalists can function as "buddies" in implementing tasks and the job scope of the journalist. The lack of rules or formality around Twitter as a platform has led journalists in creating creativity in curating news and unique identity in presenting their tweeting style, which is deemed as more honest, individualistic, and personal (Raj et al., 2015). The use of Twitter has tremendously assisted the journalists in adapting to the new norm of social media usage and the changing journalistic cultures.

Although at first, the senior journalists faced the challenges in the beginning; a positive attitude towards the new roles is observed. Being ethical is adhered to, and senior journalists felt a greater sense of responsibility when they were on social media, what they presented in their storytelling, as well as determining when and whether to post the news as many audiences can view the content instantaneously. In this sense, a journalist must realize their accountability in performing their roles., as cited in the following excerpts:

"I don't have a Twitter account before the company created one for me. They are ready for it...which is good for us...I hardly tweet at first but I realized I must try and dig more. Now I have a good number of followers. I represent the organization and must carry a good rapport. The information must be verified and I'm happy when people respond on my tweet" (SMJ 1, 2019).

"ehmmm... when you try to learn the trick and tips from social media, you realized that there's a lot of information or story you can get from Twitter. Other platforms also can be useful to me. I changed from one-two tweet per week to one-two per day. I love to interact with people before they watch my full story on prime time news" (SMJ 5, 2020).

"We must responsible for what we tweet, we must have integrity. Follow the code of ethics... it's the newsroom management concern .... We bring our organization's name. Like it or not we must be neutral on social media" (JMJ 8, 2019).

"I get more info about crime news from social media faster rather than official. I collect info from social media first, but I also have to wait from the official report to avoid misleading stories especially when it involved numbers of deaths in our reporting" (JMJ 9, 2019). 


\begin{abstract}
"ehmm...like it or not if we want to engage with the youngster, we must explore social media. Young people tend to search for information from social media platform and this is our role as a media practitioner to help fight fake news. When people search the information and get it from my verified account, they know it is true. MPB emphasize this issue" (SMJ 3, 2019).
\end{abstract}

One notable trend, the new technology is often associated with structural adjustment, and transformation to face the challenges in the newsroom. Thus, the newsroom setting and working culture will help boost journalists' confidence, and ultimately, they feel appreciated (Molyneux, Holton \& Lewis, 2017).

It was evident that the work culture of newsrooms is changing, becoming more transparent, and most importantly, media and news are now connected with respective audiences at a significantly fast speed $(\mathrm{Wu}, 2018)$. All the journalists realized the increasing need for them to be reskilled by learning new ways to handle the complexity of technology and to be multi-tasking in adapting self in the digital era.

\title{
CONCLUSION
}

According to the Malaysian Communications and Multimedia Commission (MCMC) report, 23 million Facebook accounts and 2.2 million Twitter accounts were created in Malaysia in 2018. The statistics rank Malaysia an overall tenth in Asia among the countries with the highest Facebook users (Internet World Stats, 2019). This reflected the need to relook at the strategies in presenting what is worthy to the increasing number and changing needs of the media users in the country.

The World Economic Forum report proposed a framework to measure digital media readiness (DMR) which involves the environment, capacity and usage. Based on the three factors, the readiness of those in the media industry especially journalists in Malaysia, the three digital media readiness is vital in uncovering the technological adaptation of Twitter usage in the transforming journalism practice among journalists. Indeed, the environment of the newsroom and institutional readiness assisted in upgrading the skills in utilizing Twitter among the journalists.

With the advancement of the current technology available in the media industry, anyone who holds a profession as journalists will be heavily relying on the changing media in order to deliver news, timely and creatively. Hence, mastery skills of technology adoption in their work routines is vital.

An interesting finding in this present study warrants the existence of skill gap and level of acceptance between age group involving the seniors and junior journalists at MPB in utilizing Twitter in performing their role and responsibilities as journalists. As millennial, junior journalists tweet more frequently and the fact that utilizing Twitter as a common form of communication. However, the struggle is apparent between these two groups, affecting their roles and responsibilities in the newsroom. Overall, the journalists at NCA MPB viewed Twitter as an additional source and contribution of their work.

In conclusion, the institutional readiness is, therefore, necessary to ascertain the journalist's propensity to embrace the cutting-edge technologies in performing their challenging role in the changing media industry today. Twitter usage among journalists will not be seen as replacing the conventional method of newsroom practice and creativity in presenting news but rather providing more strategies and opportunities for a news source to 
connect with the changing group of audience. Journalists of the future must be able to counter the challenges of being a conventional journalist to adapt self and engage in the digital realm.

\section{BIODATA}

Massila Hamzah, is the faculty Dean of Faculty of Communication and Media Studies, Universiti Teknologi MARA (UITM) Malaysia. Her contribution together with the faculty team, marked a significant journey for the faculty and UiTM to be the first local university to collaborate with the media giant, Al-Jazeera Media Network in Doha, Qatar, appointed as UNESCO committee member in Information for All Programme (IFAP) and International Programme for the Development Communication (IPDC) IFAP and contributed to the university's Virtual Mobility across Malaysian borders. Her research interests lie in areas of Media Sociology, Intercultural Communication and Interpersonal Communication. Email: massila@uitm.edu.my

Ima Liana Esa, is a Broadcast Journalist at TV3, Media Prima Berhad and has served the media channel since 2008. Her expertise as a Sports Broadcast Journalist has brought her around the world in performing her tasks in multi-event sports coverage such as Youth Olympics Games Singapore 2010, Asian Games Guangzhou China 2010, Asian University Games 2014, 2016, 2018, Commonwealth Games Gold Coast 2018, SEA Games 2011, 2013, 2015 and 2017. Email: lianaesa@gmail.com 


\section{REFERENCES}

Bentivegna, S., \& Marchetti, R. (2018). Journalists at a crossroads: Are traditional norms and practices challenged by Twitter?. Journalism, 19(2), 270-290. https://doi.org/10.1177/1464884917716594

Blankenship, J. C. (2015). Losing their "MOJO"?. Journalism Practice, 10(8), 1055- 1071. https://doi.org/10.1080/17512786.2015.1063080

Canter, L., \& Brookes, D. (2016): Twitter as a flexible tool. Digital Journalism, 4(7), 875-885. https://doi.org/10.1080/21670811.2016.1168707

Çatal, Ö. (2017). New technologies challenging the practice of journalism and the impact of education: Case of Northern Cyprus. Eurasia Journal of Mathematics, Science and Technology Education, 13(11), 7463-7472. https://doi.org/10.12973/ejmste/79975

Chadha, K., \& Wells, R. (2016). Journalistic responses to technological innovation in newsrooms. Digital Journalism, 4(8), 1020-1035. https://doi.org/10.1080/21670811.2015.1123100

Deuze, M., \& Witschge, T. (2018). Beyond journalism: Theorizing the transformation of journalism. Journalism, 19(2), 165-181. https://doi.org/10.1177/1464884916688550

Doctor, K. (2011). The newsonomics of a single investigative story. Nieman Journalism Lab, Retrieved on April 21, 2011, from https://www.niemanlab.org/2011/04/thenewsonomics-of-a-single-investigative-story/

Eni Maryani, Detta Rahmawan, \& Siti Karlinah. (2020). The implications of social media on local media business: Case studies in Palembang, Manado and Bandung. Jurnal Komunikasi: Malaysian Journal of Communication, 36(1), 317-333.

Elias, S., Smith, W., \& Barney, C. (2012). Age as a moderator of attitude towards technology in the workplace: Work motivation and overall job satisfaction. Behaviour \& Information Technology, 31, 453-467.

Groshek, J., \& Tandoc, E. (2017). The affordance effect: Gatekeeping and (non) reciprocal journalism on Twitter. Computers in Human Behavior, 66, 201-210. https://doi.org/10.1016/j.chb.2016.09.020

Hanusch, F. (2019). Journalistic roles and everyday life. Journalism Studies, 20(2), 193-211. https://doi.org/10.1080/1461670X.2017.1370977

Hanusch, F., \& Bruns, A. (2016). Journalistic branding on Twitter. Digital Journalism, 5(1), 2643. https://doi.org/10.1080/21670811.2016.1152161

Heravi, B. R., \& Harrower, N. (2016). Twitter journalism in Ireland: Sourcing and trust in the age of social media. Information, Communication \& Society, 19(9), 1194-1213. https://doi.org/10.1080/1369118X.2016.1187649

Kröll, A. (2015). The role of journalism in the digital age being a superhero or Clark Kent: Do journalists think that networked journalism is an appropriate tool to work with (in the future)?. Reuters Institute. Retrieved from https://reutersinstitute.politics.ox.ac.uk/our-research/role-journalism-digital-age

Lareau, L. (2017). The impact of digital technology on media workers: Life has completely changed. Ephemera, 10, 522-525. Retrieved from http://www.ephemerajournal.org/contribution/impact-digital-technology-mediaworkers-life-has-completely-changed

Laor, T., \& Galily, Y. (2020). Offline VS online: Attitude and behavior of journalists in social media era. Technology in Society, 61, 101239. https://doi.org/10.1016/j.techsoc.2020.101239 
Lee, S. K, Lindsey, N. J \& Kim K.S. (2017). The effects of news consumption via Social Media and news information overload on the perceptions of journalism. Computers in Human Behavior, 75, 254-263. https://doi.org/10.1016/j.chb.2017.05.007

Malia Taibi, \& Teh, Y. N. (2020). The changes of media landscape in Malaysia: How citizen journalism poses threats to traditional media. Jurnal Komunikasi: Malaysian Journal of Communication, 36(1), 369-380.

Molyneux, L., Holton, A., \& Lewis, S. C. (2017). How journalists engage in branding on Twitter: individual, organizational, and institutional levels. Information, Communication \& Society, 21(10), 1386- 1401. https://doi.org/10.1080/1369118x.2017.1314532

Normah Mustaffa, Shahrul Nazmi Sannusi, Ahmad Sauffiyan Abu Hasan, \& Mohd Zuwairi Mat Saad. (2017). Journalism and news industry in Malaysia: New media, new challenges. E-Bangi Journal, 12(2), 73-80.

Raj, S. J., Sreekumar, R., \& Kalorth, N. (2015). Tweeting the news-twitter Journalism as a new age crowd news in India. European Academic Research, 1, 4536-4571.

Wan Hartini Wan Zainodin. (2018). Understanding the engagement and consequences of user generated online video and its virality towards generation $Y$ political inclination (Doctoral dissertation, Universiti Teknologi MARA, Malaysia). Retrieved from http://ir.uitm.edu.my/id/eprint/22262

$\mathrm{Wu}$, Y. (2018). How age affects journalists' adoption of social media as an innovation. Journalism Practice, 13(5),

537-557. htpps://doi.org/10.1080/17512786.2018.1511821 